NASA Technical Memorandum 83724

\title{
An Investigation of the Transient Thermal Analysis of Spur Gears
}

Lotfi E. El-Bayoumy and Lee S. Akin

California State University at Long Beach

Long Beach, California

and

Dennis P. Townsend

Lewis Research Center

Cleveland, Ohio

Prepared for the

Fourth International Power Transmission and Gearing Conference sponsored by the American Society of Mechanical Engineers

Cambridge, Massachusetts, October 10-12, 1984 
AN INVESTIGATION OF THE TRANSIENT THERMAL ANALYSIS OF SPUR GEARS

Lotfi E. El-Bayoumy and Lee S. Akin

California State University at Long Beach

Long Beach, California

and

Dennis $P$. Townsend

National Aeronautics and Space Administration

Lewts Research Center

Cleveland, Ohio 44735

\section{ABSTRACT}

A finite element computer program has been developed for evaluating the transient behavior of surface temperature in high performance spur gears. The program is an extension of a previously developed code that was limited to steady state behavior. The time dimension is implemented using two and three point finite difference schemes. The different schemes are provided to the user for the purpose of numerical stablilty and convergence studies.' A detailed explanation of the gear cooling process leading to the establishment of a modified Blok model is also included. Other conventional models for approximating the heat transfer coefficients are available for comparison. Preliminary results are given showing snap shots of gear temperature contours at the initial stages of tooth engagement.

\section{INTRODUCTION}

Amongst the three modes of gear fallure, scoring is known to be the most troublesome in high speed case hardened gearing. Experimental evidence [1] has shown that a sudden surge of the flash temperature of the gear takes place at the onset of scoring. Because of the interdependence of the flash and bulk temperatures of the gear, an accurate prediction of the latter is highly desirable. Recently in Refs. 1 to 3 a finite element approach has been successfully 
applied to the estimation of bulk temperatures of a pair of meshing gears at steady state operation. The temperature distribution within each tooth is assumed to be identical and all transient effects are neglected. A variety of models were used to approximate the convective heat transfer coefficients within the elastohydrodyanmic film attached to the tooth profile. The effects of 011 jet cooling and 011 jet impingement depth were included in Refs. 1 and 3 . Because of the highly transient nature of thermal behavior at the onset of scoring a transient thermal analysis of the meshing gears would be extremely useful. Furthermore since the heat transfer coefficients, as will be shown in the text, are themselves time dependent functions, a steady state approach could not be used without major averaging approximations.

The intent of this paper is to describe a computer analysis procedure for the transient thermal analysis of spur gears using the finite element method. The finite element equations are derived using the well known Galerkin or weighted residual approach as explained in detall in Ref. 4 . The heat flux input generated due to friction between the meshing gears is derived as a time dependent function unlike the heat flux used in the steady state solutions of Refs. 1 to 3. Two separate models have been programmed into the computer code for approximating the convective heat transfer process within the cooling film. The first allows the use of fixed heat transfer coefficlents along the various sections of the gear profile as in Refs. 1 to 3 for the purpose of comparison with the steady state solution obtained therein. The second uses an array of time dependent heat transfer coefficients based on an asymptotic solution to the one-dimensional heat transfer equation as shown in the text. 
Derivation of Finite Element Equations for Transient Heat Transfer in Gearing

It is shown in Ref. 3 that the majority of heat dissipation occurs at the tooth boundary. Therefore at the expense of little loss in accuracy, it can be assumed that the temperature within one tooth is independent of those within the neighboring teeth. This justifies the use of the one tooth sector model shown in Fig. 1, instead of the whole gear.

The partial differential equation governing heat transfer within the identified region is given by

$$
\frac{\partial^{2} \theta}{\partial x^{2}}+\frac{\partial^{2} \theta}{\partial y^{2}}+c_{a} \frac{\partial^{2} \theta}{\partial z^{2}}-\alpha R_{0}^{2} \frac{\partial \theta}{\partial t}=0
$$

where

$$
\begin{gathered}
c_{a}=\left(\frac{2 R_{0}}{F}\right)^{2} \\
x=\frac{x}{R_{0}}, y=\frac{y}{R_{0}}, z=\frac{z}{F / 2} \\
\theta=\frac{k P_{d}\left(T-T_{a}\right)}{q_{a v}}
\end{gathered}
$$

$T$ Current gear temperature, ${ }^{\circ} \mathrm{C}\left({ }^{\circ} \mathrm{F}\right)$

$T_{a}$ Initial gear temperature, ${ }^{\circ} \mathrm{C}\left({ }^{\circ} \mathrm{F}\right)$

a Gear diffusivity, $\mathrm{m}^{2} / \mathrm{sec}\left(\mathrm{in} .^{2} / \mathrm{sec}\right.$ )

c Specific heat of gear material, $\mathrm{J} / \mathrm{kg}{ }^{\circ} \mathrm{K}\left(\mathrm{Btu} / \mathrm{lb}{ }^{\circ} \mathrm{F}\right)$

$k$ Thermal conductivity of gear material, W/m ${ }^{\circ} \mathrm{K}$ (Btu/ft ${ }^{\circ} \mathrm{F}$ )

$R_{0} \quad$ Outside radius of gear, $m(f t)$

F Face width of gear, $m(f t)$

$q_{a v}$ Average heat flux through the gear profile, w/hr (Btu/hr)

The assoclated boundary conditions are 


$$
\begin{gathered}
\frac{\partial \theta}{\partial \bar{n}}+\frac{h_{t}(s, t) R_{0}}{k} \theta-P_{d} R_{0} q^{*}=0 \text { on } \Gamma_{1} \\
\frac{\partial \theta}{\partial \bar{n}}+\frac{h_{t}(s, t) R_{0}}{k} \theta=0 \text { on } \Gamma_{t} \\
\frac{\partial \theta}{\partial z}+\frac{h_{s}(t) F}{2 k} \theta=0 \text { on } \Gamma_{s}
\end{gathered}
$$

where

$\bar{n} \quad \frac{n}{R_{0}}$

$n$ normal coordinate to the tooth profile

$h_{t}$ convective heat transfer coefficient in tooth profile, $W / h^{-}-m^{2}{ }^{\circ} \mathrm{K}$ (Btu/hr $\mathrm{ft}^{2} \circ \mathrm{F}$ )

$h_{s}$ convective heat transfer coefficient on front and back faces of gear

$p_{d}$ diametral pitch of gear. $m^{-1}(i n .-1)$

$q^{\star} \quad q / q_{a v}$

$r_{1}$ tooth involute boundary, loaded side

$r_{t}$ tooth involute boundary, coast side

$r_{s}$ front and back end faces of tooth

Discretization in the space domain is accomplished through the use of the Galerkin approach [4] in conjunction with the trial function.

$$
\theta(x, y, z, t)=\sum N_{f}(x, y, z) \underset{\sim}{\theta}(t) \equiv \underset{\sim}{N} \underset{\sim}{\theta}
$$

where $N_{1}$ are the spatial shape functions chosen as [2]

$$
N_{1}=\frac{1}{2 \Delta}\left(a_{1}+b_{1}+c_{1} y\right)\left(1-B z^{2}\right)
$$

The Galerkin principle yields the following first order equation

$$
\underset{\sim}{\stackrel{\theta}{\theta}}+\underset{\sim}{H} \underset{\sim}{\theta}+\underset{\sim}{P}=0
$$


where

$$
\begin{aligned}
& \left({ }^{\circ}\right) \equiv \frac{d}{d t}() \\
& c_{i j} e=\int_{-1}^{1} \int_{-\Omega} e N_{1}+N_{j} d \Omega d z \\
& H_{1 j}=\int_{-1}^{1} \int_{\Omega} \nabla^{\top} N_{1} \nabla N_{j} d \Omega d z-\int_{\Gamma} N_{1} \bar{a} N_{j} d \Gamma \\
& P_{1}=-\int_{\Gamma} N_{1} \bar{q} d \Gamma \\
& \mu=\frac{\rho C R_{0}^{2}}{k} \\
& \bar{\alpha}= \begin{cases}\frac{h_{t} R_{0}}{k} & \text { on } \Gamma_{t} \\
\frac{h_{s} F}{2 k} & \text { on } \Gamma_{s}\end{cases}
\end{aligned}
$$

Proceedings in the manner described by Zienkiewicz [4] for discretization in the time domain such that

$$
\underline{\theta}(t) \simeq \underline{\sim}_{\hat{\theta}}(t)=\sum L_{1}(t) \stackrel{\theta}{1}_{1}
$$

where $L_{i}(t)$ are time dependent shape functions and $\Phi_{i}$ represents $\hat{\Phi}$ at node $n$ the time dimension. These are given as

$$
\begin{aligned}
& L_{n}=1-\xi \\
& L_{n+1}=\xi
\end{aligned}
$$

where

$$
\xi=t / \delta t
$$

Applying the Galerkin principle to Eq. (6) by integrating its weighted average over a time element, it follows that

5 


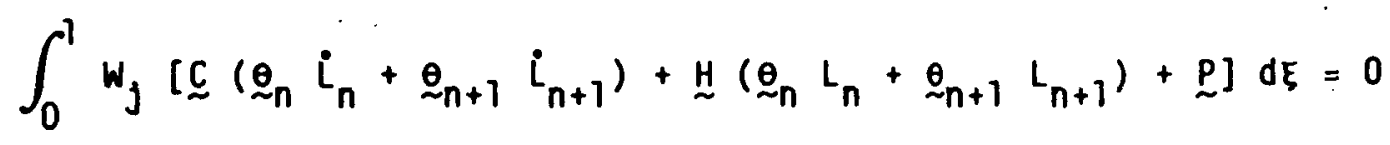

where $W_{j}$ is any appropriately chosen weighting function of time $(\varepsilon)$. Noting the definitions of $L_{n}$ and $L_{n+1}$ in Eq. (9), the following recurrence relation for $\Phi_{n}$ is obtained.

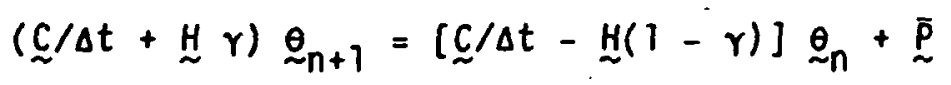

where

$$
\begin{aligned}
& r=\int_{0}^{l} w_{j} \xi d \xi / \int_{0}^{l} w_{j} d \xi \\
& \underset{\sim}{p}=\int_{0}^{1} w_{j} \stackrel{p}{\sim} d \xi / \int_{0}^{l} w_{j} d \xi
\end{aligned}
$$

If a shape function expansion similar to Eq. (8) is used to express the heat input term $\underset{\sim}{\bar{p}}$, the last of Eq. (12) becomes

$$
\underset{\sim}{\bar{P}}={\underset{\sim n+1}{P}}_{p} r+{\underset{\sim n}{p}}_{n}(1-\gamma)
$$

A variety of numerical schemes such as the Euler, Crank-Nicholson, backward difference etc. are the results of Eq. (11) for various assumptions of the weighting function $w_{j}$ (see [4] for detalls). It can be shown that $0<r<1$ and that for numerical stability $y>1 / 2$.

\section{Derivation of Time Dependent Frictional Heat Input}

The steady-state heat flux input generated in friction between the two meshing gears was derived in [1] as:

$$
q_{1}=\frac{f W_{1}}{2 J}\left|1-\frac{N_{1}}{N_{2}}\left(\frac{L_{A}-p_{1}}{\rho_{1}}\right)\right|
$$

where the subscript 1 refers to the instantaneous point of contact along the tooth profile. Because the analysis in [1] was restricted to steady state 
running, the heat flux along the entire tooth profile was simultaneously applied. In the present transient analysis, the instantaneous flux $q_{1}^{t}$ at a time instant $t_{\mathfrak{q}}$ is therefore given as

$$
q_{1}^{t}=q_{1} \delta\left(t-t_{1}\right)
$$

where $\delta_{t}$ is the Dirac delta function and $a_{1}$ is given by Eq. (13).

The computer program is designed to calculate, if and when the two gears are in contact, the corresponding roll angle measured from the beginning of engagement at the outer tip of gear and the corresponding radius of curvature $P_{1}$. No heat input is generated beyond the lowest point of contact until the next time the tooth under consideration is engaged.

\section{Convective Heat Transfer Models}

At the present time two basic options are avallable in the program. The first enables the user to use constant heat transfer coefficients individualized in the manner described in [1]. These are presumably derived experimentally and averaged out over the expected temperature range of the gear tooth. In this model no convective heat dissipation is assumed to take place beyond the fling-off angle and until the tooth is reengaged.

The other model for heat convection is based on an asymptotic solution of the heat transfer equation along the tooth profile such that

$$
\frac{\partial T}{\partial t}=\alpha \frac{\partial^{2} T}{\partial y^{2}}
$$

The exact solution of $\mathrm{Eq} .(15)$ for a constant temperature along the tooth profile gives the heat transfer coefficient at any instant $t$ as

$$
h_{j}=K /(\pi \alpha t)^{1 / 2}
$$


where $K$ is the thermal conductivity of the 011 . Again in this model no heat dissipation is assumed to take place beyond the fling off angle and until the tooth is reengaged.

The amount of heat flux dissipated in convection is given by

$$
q_{0}=h A \Delta T
$$

where $h$ may be assigned fixed values, while the tooth is being cooled, or the program is instructed to calculate the current value of $h$ from Eq. (16).

\section{RESULTS AND DISCUSSION}

The recurrence formula of Eq. (II) above constitutes a set of nonhomogeneous algebraic equations for the dimensionless temperature array $\underset{\sim}{\Theta}+1$ at a time node $n+1$ in terms of the temperature array $\underset{\sim}{\underset{n}{\theta}}$ at the preceding time node $n$ and the dimensionless heat flux array $\underset{\sim}{\mathbb{S}}$. It should be noted that the latter is made of a linear combination of the heat fluxes at times $n$ and $n+1$, as deflned in Eq. (13). Based on recommendations of well known finite element programs such as NASTRAN [5] the weighting factor $\gamma$, convectionally known as a finite difference parameter, is assigned a value of 0.55 . This value has been found to yleld rapid convergence and greater accuracy for problems with known exact solutions. The computational technique consists of a standard initial value problem algorithm in which the initial temperatures are assumed and heat flux vector is computed from Eqs. (14) and (15). A Cholesky decomposition is then administered. to Eq. (11) to facilitate the solution [6].

The finite element grid used for computation is shown in Fig. 2 in which the tooth is divided into 18 layers of triangular elements using the gear finite element generator program ATOGEN. It was shown in Ref.3 that in the steady state case, this mesh yielded results of sufficient accuracy. The example run is that of the NASA four square testing apparatus described in Ref. 1 . 
The temperature distribution within the tooth is convenientiy represented in the computer output in the form of constant contour lines as 1llustrated in Figs. 3 to 7. Each figure represents a chronological set of "snap shots" for the pinion tooth as it traverses the line of action between the highest and lowest points of contact.

All the computer runs were made using an 8 pitch $8.89 \mathrm{~cm}(3.5 \mathrm{in}$.$) pitch$ diameter, $0.635 \mathrm{~cm}(0.25 \mathrm{ln}$.$) wide spur gear operating at 10000 \mathrm{rpm}$ with a normal load of $5912 \mathrm{~N} / \mathrm{cm}(3378 \mathrm{lb} / \mathrm{in}$.$) and a dimensioniess o11 jet impingement$ depth of 0.336 .

In Figs. 3(a) to (d) (Case 1 ) the heat transfer coefficients for the different regions of the gear tooth model ( $f \mathrm{gg} .1$ ) are assumed constant during the perlod of contact and their values are identical with those used in Refs. 1 and 3 for the steady state temperature survey of the subject gear and were $H_{s}=0.6$ for the sides of the tooth, $H_{t}=3.0$ for the tooth flank surfaces without oil jet cooling, $H_{j}=13$ for tooth flank surface with ofl jet cooling and $H_{j t}=3.0$ for top land of tooth with 011 jet cooling. As noted in Ref. 1, those values were obtained in an iterative manner to yield best correlation with test data. The temperature contours are seen to be crowded around the point of contact, a would be expected, since the heat source at that instant of time coincides with that point. The maximum temperature at any instant during the mesh cycle always occurs at the instantaneous point of contact. The contours proceed to propagate and spread out down the tooth profile. It is interesting to note that closed loop contours are occasionaliy observed within the gear tooth indicating the presence of local maxima in the thermal topology of the tooth. These contours continue to propagate away from the contact point towards the unloaded coast side until they totally disappear. 
The temperature contours at the same instants of time are reproduced in Figs. 4(a) to (d) (Case 2) using a heat transfer coefficient $h_{j}$ obtained from the time dependent Eq. (16). Gear cooling is constrained to the loaded side of the tooth above the lowest point of contact. The initial distribution of temperature is significantly different from the preceding case for the recess portion of contact, up to the pitch point, where the distribution approaches the case of steady heat transfer coefficients. In fact the maximum temperature rise during the contact period is nearly the same for the two cases $\left(14.18^{\circ} \mathrm{C}\right.$ for case 1 versus $14.11^{\circ} \mathrm{C}$ for case 2$)$.

Case 3 (figs. 5(a) to. (d)) plots pertain to cooling of the top land in addition to the loaded portion of the tooth. Comparison of Fig. 5 with Fig. 4 indicates no significant change with the additional cooling from the top land. One may therefore suggest that cooling the top land is of little or no benefit in reducing the bulk temperature of the gear. More study is required before this will be conciusive. The maximum temperature rise during the first engagement cycle for this case is found to be $14.03^{\circ} \mathrm{C}$.

The remaining two cases consider the addition of cooling to the coast side of the tooth as well as the transverse planes of the gear. Because the translent heat transfer formula, Eq. (16) is independent of temperature (except implicitly through the thermal conductivity $k$ and diffusivity $\alpha$ ), the instantaneous heat transfer coefficients used for all regions of the tooth are identical. Although this is far removed from practice, it is interesting to note the significant drop in temperature as a result of cooling the ends and coast sides of the tooth. The maximum temperature rise is only a fraction of that computed for cases 1 to. 3. The temperature contours are now continuously crowded around the contact point with most of the tooth remaining at the initial temperature. 
An attempt was made to modify the heat transfer coefficients by multiplying them by a correction factor proportional to the steady state heat transfer coefficients, 1.e., $H_{s} \times .6 / 13, H_{t} \times 3 / 13, H_{J} \times 13 / 13$ and $H_{J t} \times 3 / 13$. The resulting contour plots are not shown in this paper because of their similarity to Figs. 6 and 7.

The reduction in maximum temperature is still very significant, although not as drastic as shown in cases 4 and 5 (figs. 6 and 7 ) ( $\Delta T \max =6.03^{\circ} \mathrm{C}$ not shown versus $2.97^{\circ} \mathrm{C}(\mathrm{fig} .6(d))$.

Figure 8 fllustrates how the instantaneous maximum temperature varies with time (or pinion rotation angle) such as would be detected in an experimental measurement. Although no experimental results are avallable at this time for the initial stages of engagement, the wavy patterns obtained in Fig. 8 resemble those for the experimental data shown in Ref. 1. The minimum temperature noted in the graph is clearly associated with the pitch point, where pure rolling takes place and friction losses are negligible.

\section{SUMMARY OF RESULTS}

A finite element computer program has been developed for evaluating the transient behavior of surface temperature in high performance spur gears. The program is an extension of a previously developed code that was limited to steady state behavior. The time dimension is implemented using two and three point finite difference schemes. The different schemes are provided to the user for the purpose of numerical stablitty and convergence studies. A detailed explanation of the gear cooling process leading to the establishment of a modified Blok model is also included. The following results were obtained:

(1) The maximum temperature obtained with constant heat transfer coefficlents, used to predict steady state conditions, is nearly the same as that obtained from a time-dependent modified Blok model when heat dissipation is constralned to the loaded side of the tooth. 
(2) Cooling of the top land was found to be of no benefit in reducing gear temperature.

(3) Cooling of coast side of the tooth was, on the other hand, of great significance and should be utilized whenever possible.

(4) The temperature rise along the recess portion of the gear tooth is markedly lower than the approach portion. It should be advantageous, therefore, to use recess-action type gears to preclude scoring.

\section{ACKNOWLEDGEMENT}

The authors would like to thank or. John Murdock for deriving the transient formula of the heat transfer coefficient.

\section{REFERENCES}

1. Townsend, O. P., and Akin, L. S., "Analytical and Experimental Spur Gear Tooth Temperature as Affected by Operating Variables," Journal of Mechanical Design, Vol. 13, No. 4, Jan. 1981, pp. 219-226.

2. Patir, N., and Cheng, H. S., "Prediction of Bulk Temperature in Spur Gears Based on Finite Element Temperature Analysis," ASLE preprint No. 77-LC-38-2, Oct. 1977 .

3. El-Bayoumy, L. E., Akin, L. S., and Townsend, D. P., "Parameter Studies of Gear Cooling Using an Automatic Finite Element Mesh Generator," submitted for presentation at the ASME Fourth Int. Power Trans. and Gearing Conference, Cambridge, MA, Oct. 1984.

4. Aienkiewicz, 0. C., The Finite Element Method, McGraw-Hi11, New York, 1977. pp. 569-604.

5. MacNeal, R. H., The Nastran Theoretical Manual, Level 15.5, MacNeal-Schwendler Corporation, Dec. 1972, Pp. 8.4-7 to 8.4-12.

6. Segerlind, L. J., Applied Finite Element Analysis, Wiley, New York, 1976. 

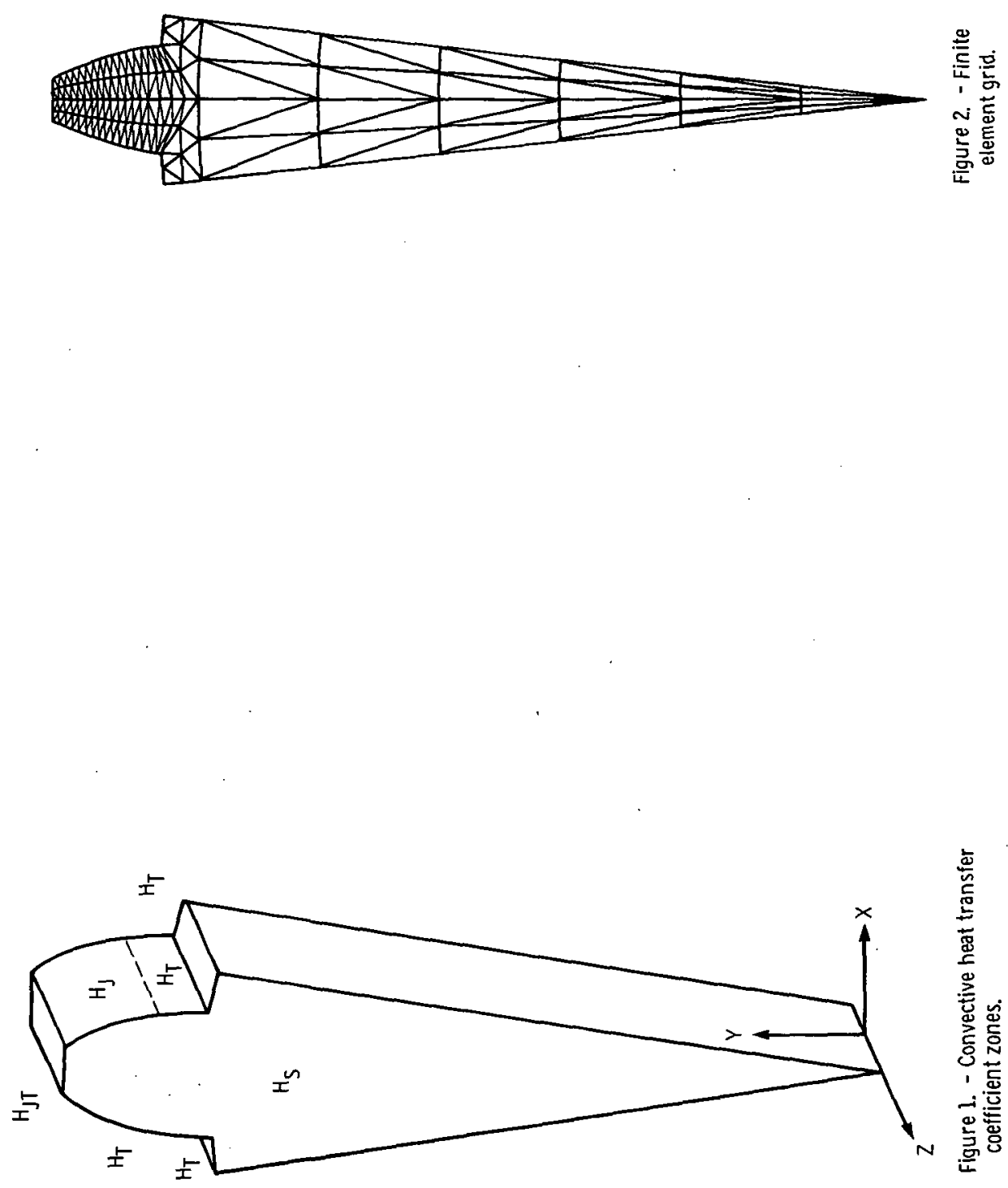


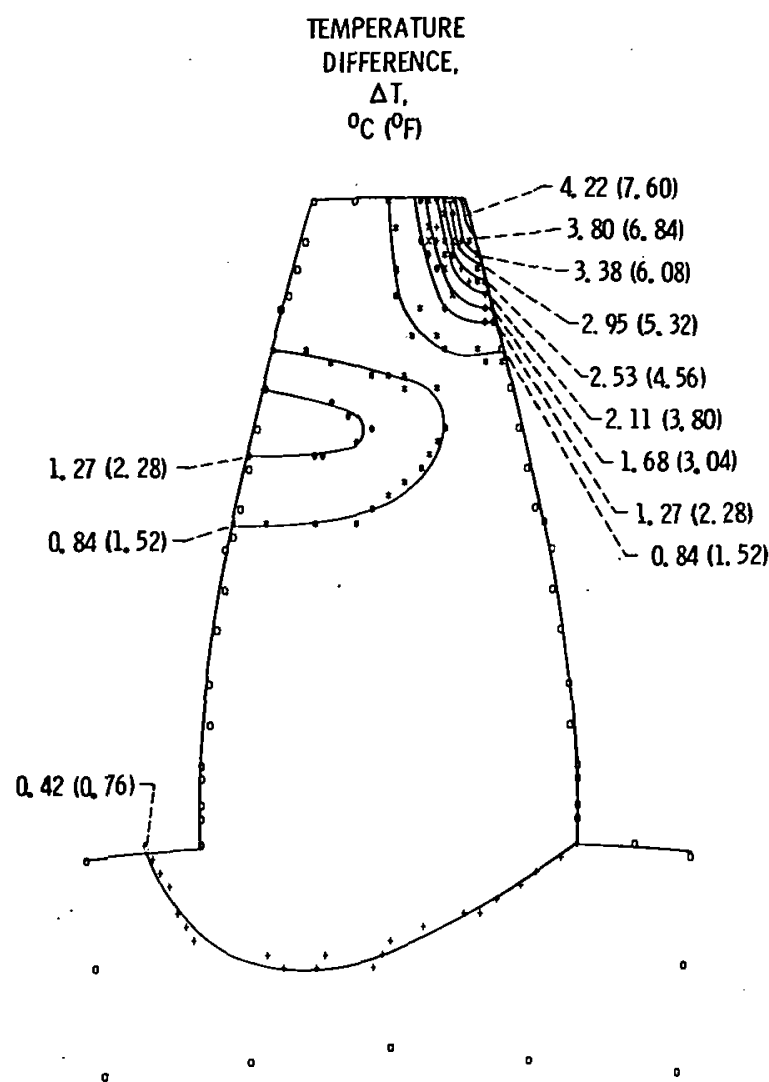

(a) Pinion rotation angle, $0.72^{0}$; time, $0.012 \times 10^{-3}$ seconds from point of initial tooth contact.

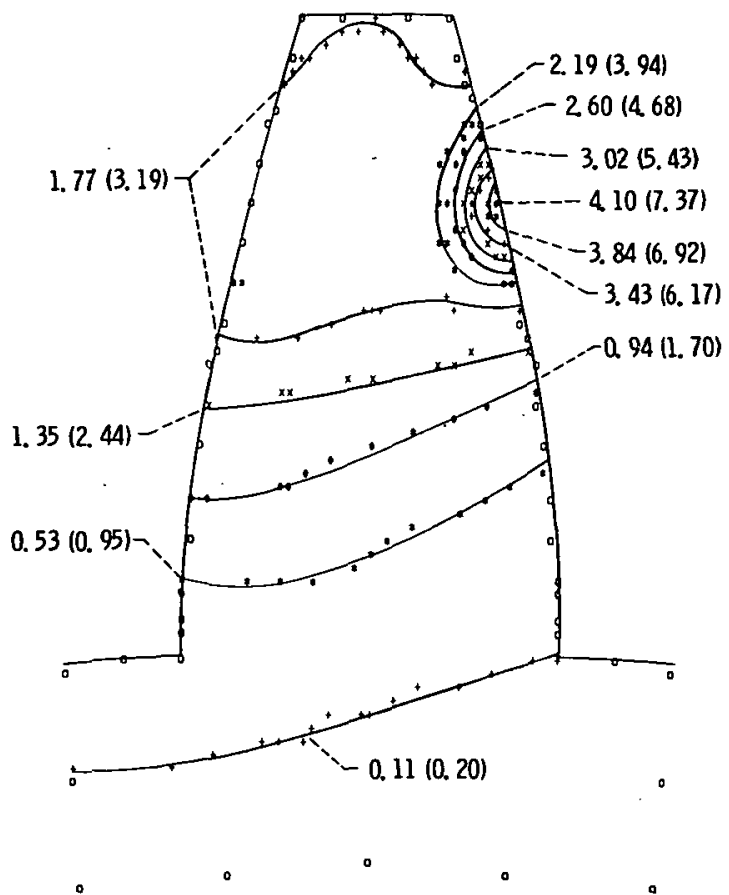

(b) Pinion rotation angle, $5.04^{0}$; time, $0.08 \times 10^{-3}$ seconds from point of initial tooth contact.

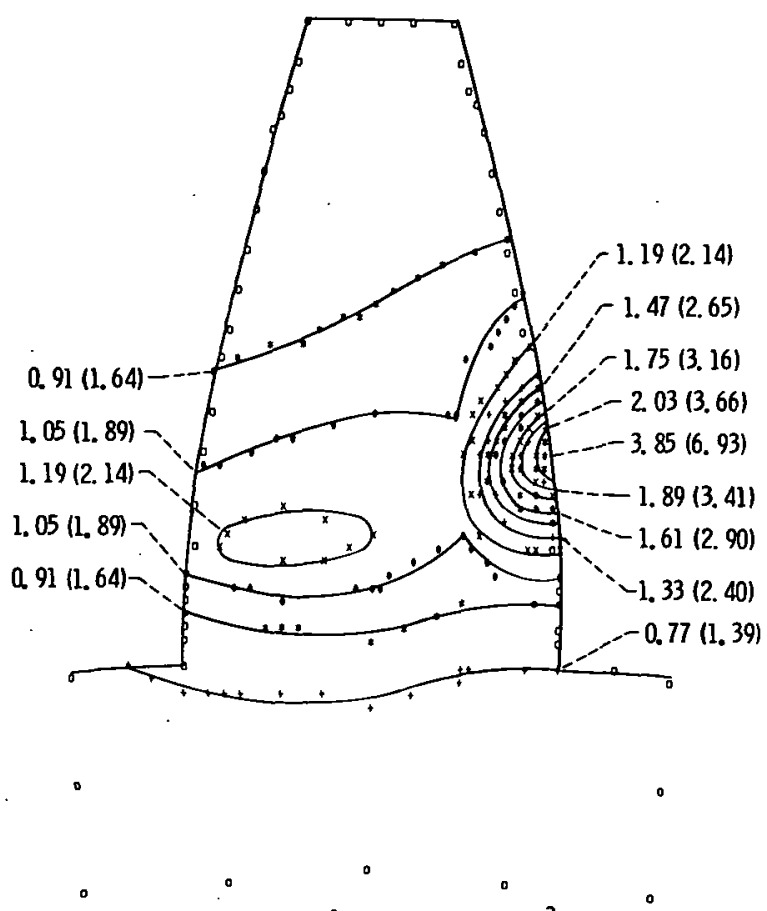

(c) Pinion rotation angle, $13.68^{0}$; time, $0.228 \times 10^{-3}$ seconds from point of initial tooth contact.

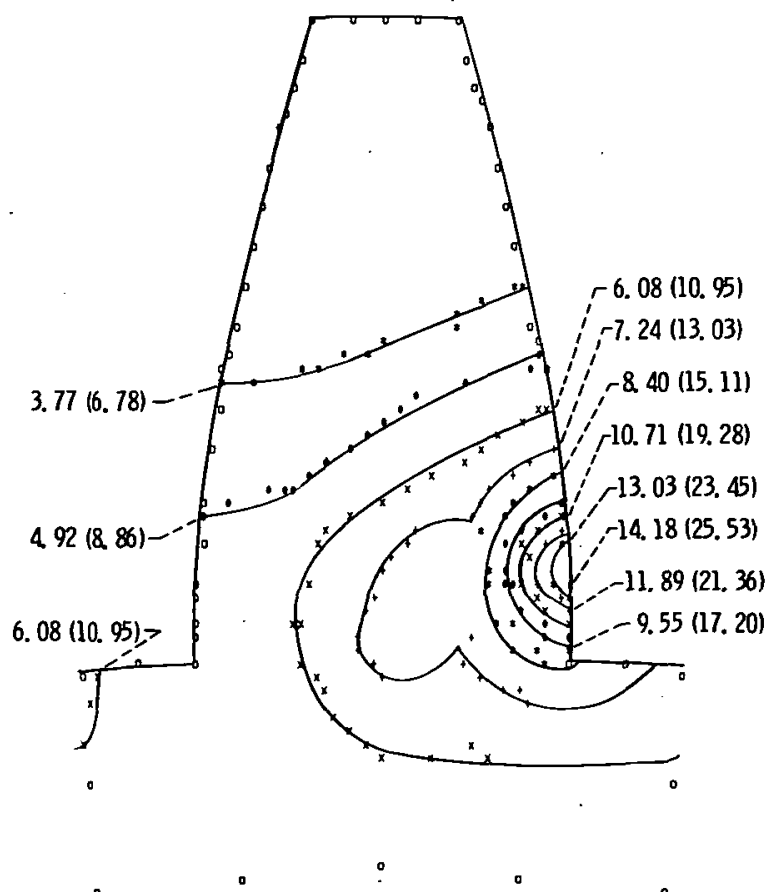

(d) Pinion rotation angle, $20.88^{\circ}$; time, $0.348 \times 10^{-3}$ seconds from point of initial tooth contact.

Figure 3. - Transient temperature isotherms using steady state heat transfer coefficients $H_{s}, a_{6} ; H_{t}$ and $H_{i t,}, 3 ; H_{j}$, 13. For 8-pitch spur gear : pitch diameter, $8.89 \mathrm{~cm}(3.5 \mathrm{in}$.): face width, $0.635 \mathrm{~cm}(0.25 \mathrm{in}$.): speed, $10000 \mathrm{rpm}$; load, $5912 \mathrm{~N} / \mathrm{cm}$ (3378 lb/in.); dimensionless impingement depth, 0.336 . 


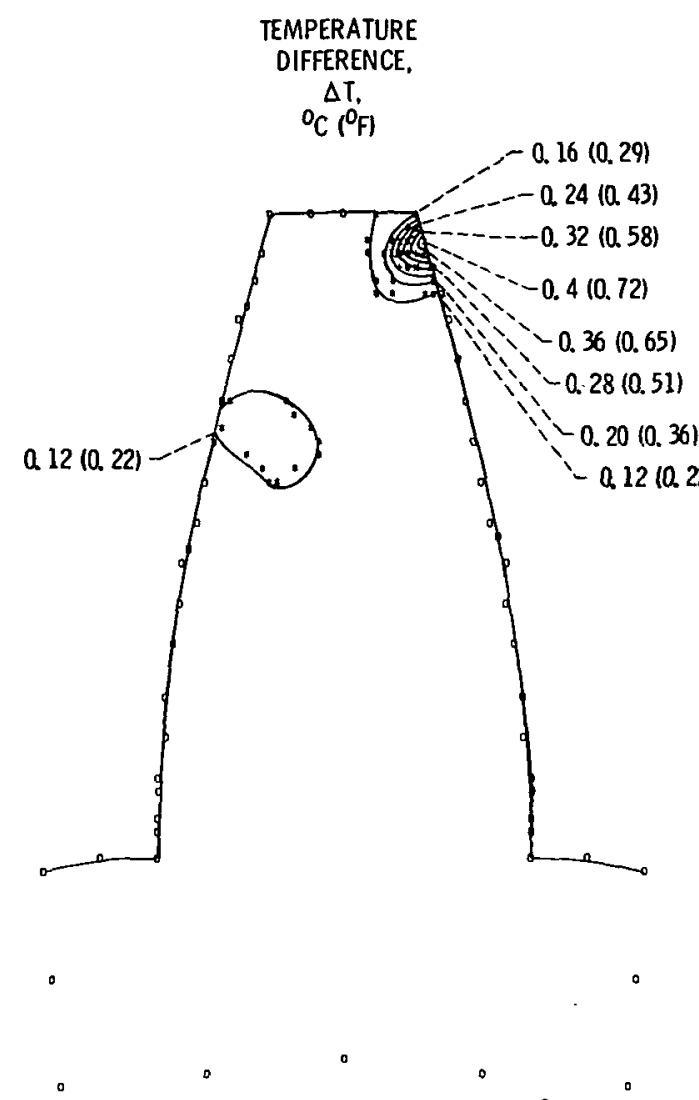

(a) Pinion rotation angle, $0.72^{0}$; time, $0.012 \times 10^{-3}$ seconds from point of initial tooth contact.

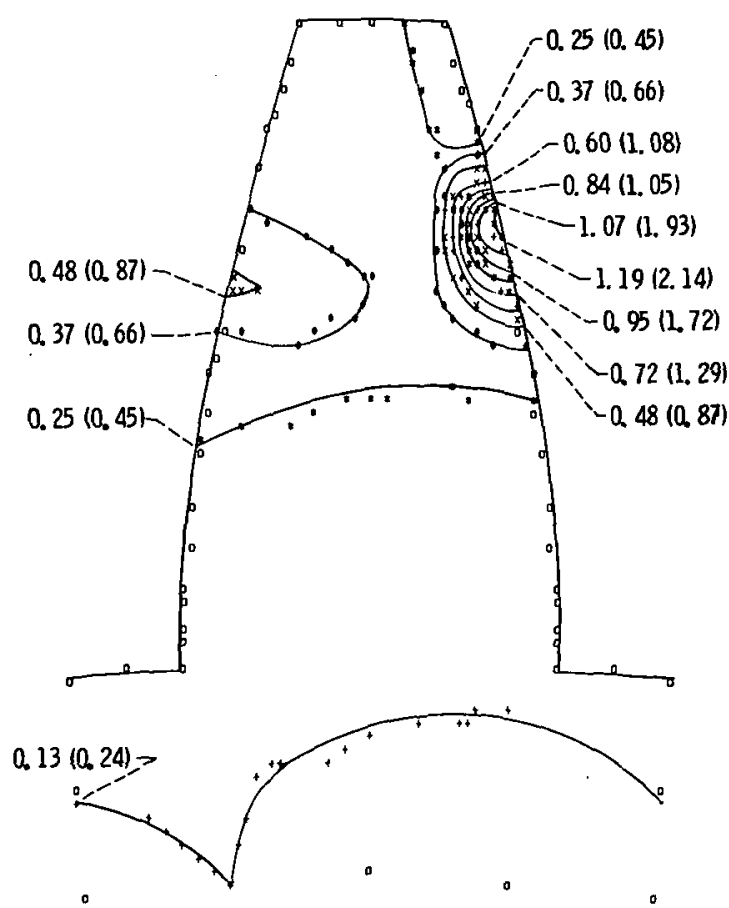

(b) Pinion rotation angle, $5.04^{0}$; time, $0.08 \times 10^{-3}$ seconds from point of initial tooth contact.

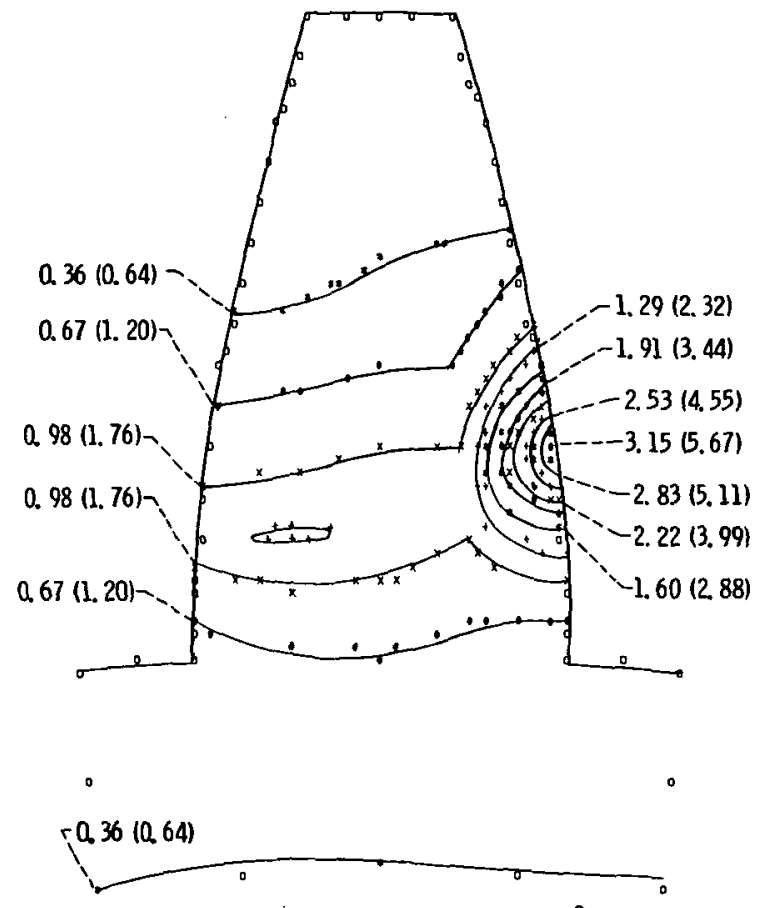

(c) Pinion rotation angle, $13.68^{\circ}$; time, $0.228 \times 10^{-3}$ seconds from point of initial tooth contact.

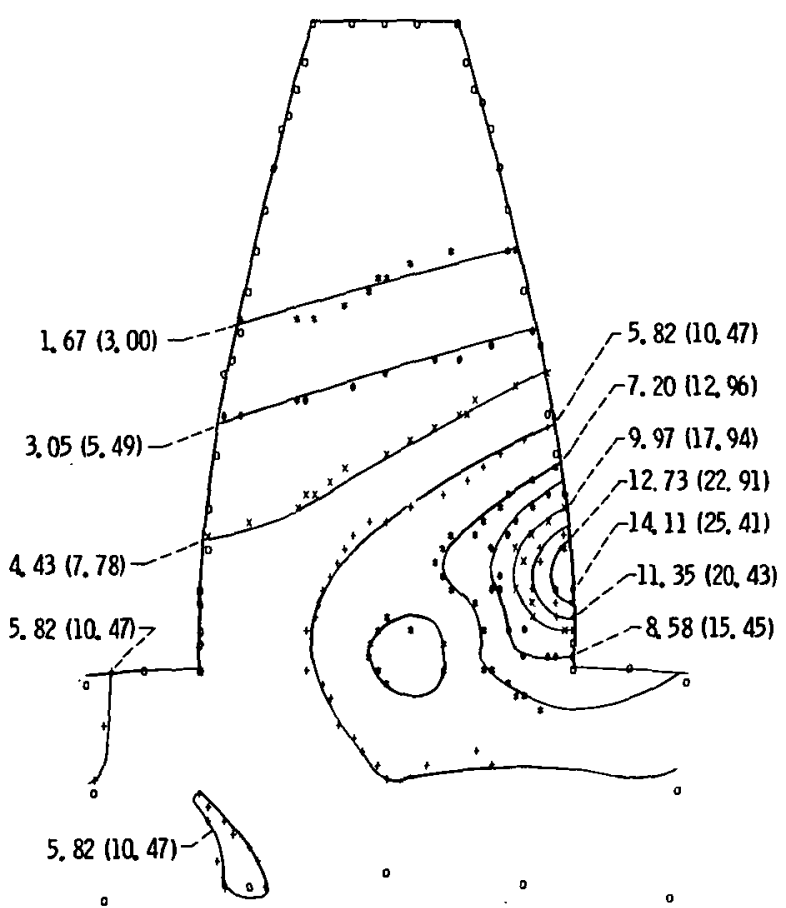

(d) Pinion rotation angle, $20.88^{\circ}$; time, $0.348 \times 10^{-3}$ seconds from point of initial tooth contact.

Figure 4. - Transient temperature isotherms using transient thermal analysis with computed heat transfer coefficients, load side cooling only. For 8-pitch

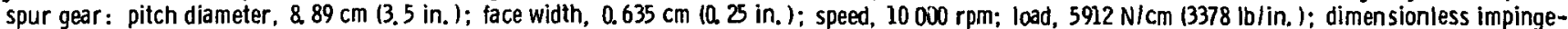
ment depth, Q.336. 


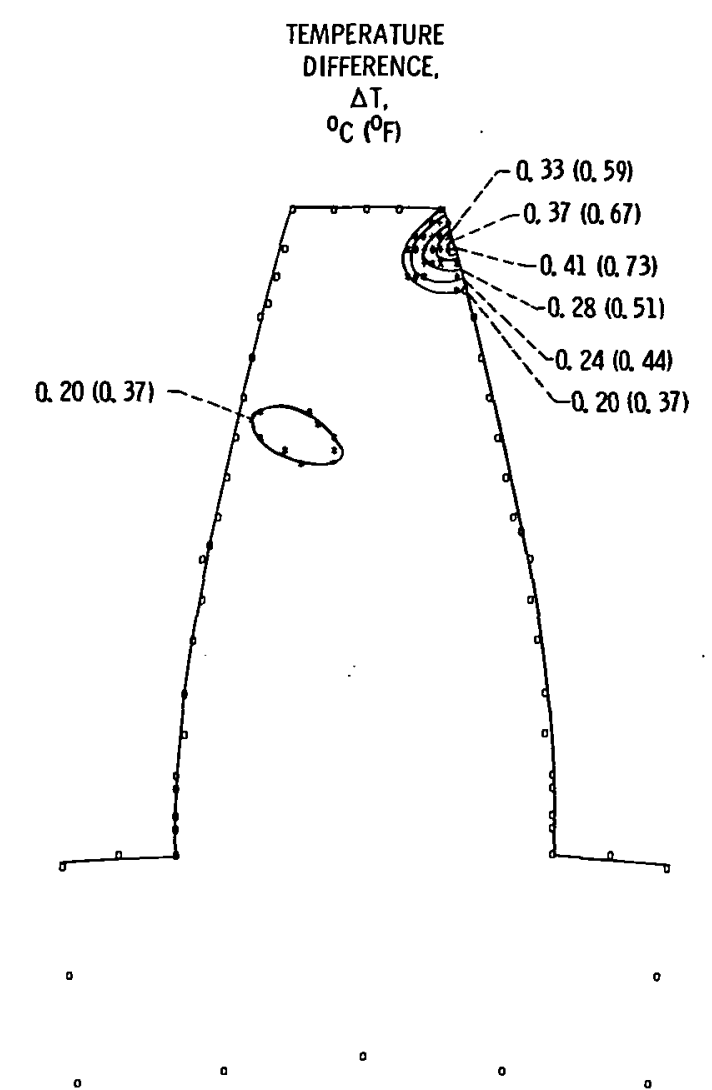

(a) Pinion rotation angle, $0.72^{0}$; time, $0.012 \times 10^{-3}$ seconds from point of initial tooth contact.

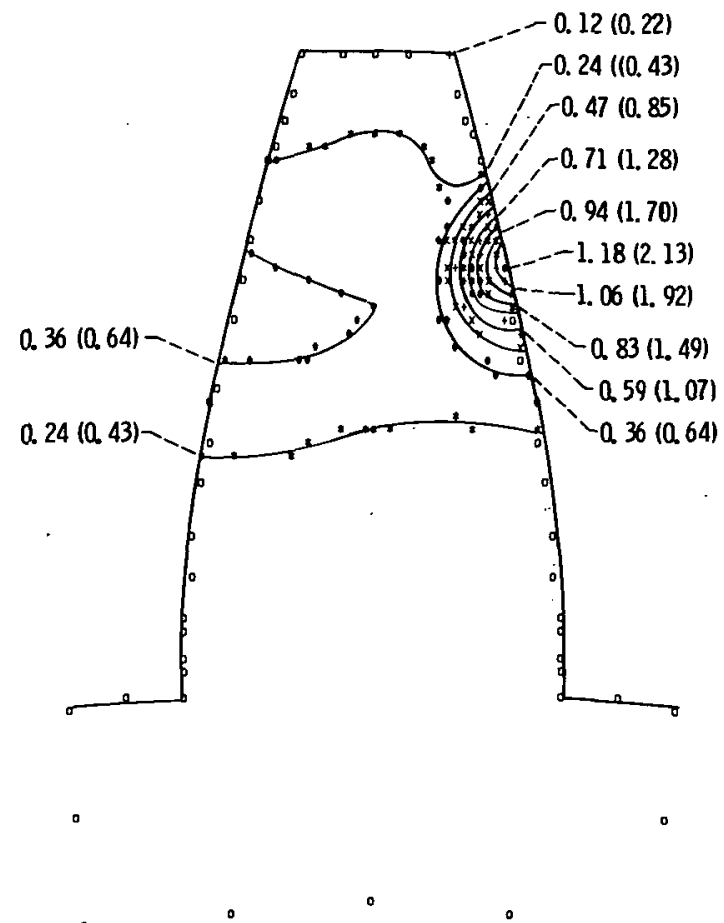

(b) Pinion rotation angle, 5. 04; time, a. $08 \times 10^{-3}$ seconds from point of initial tooth contact.

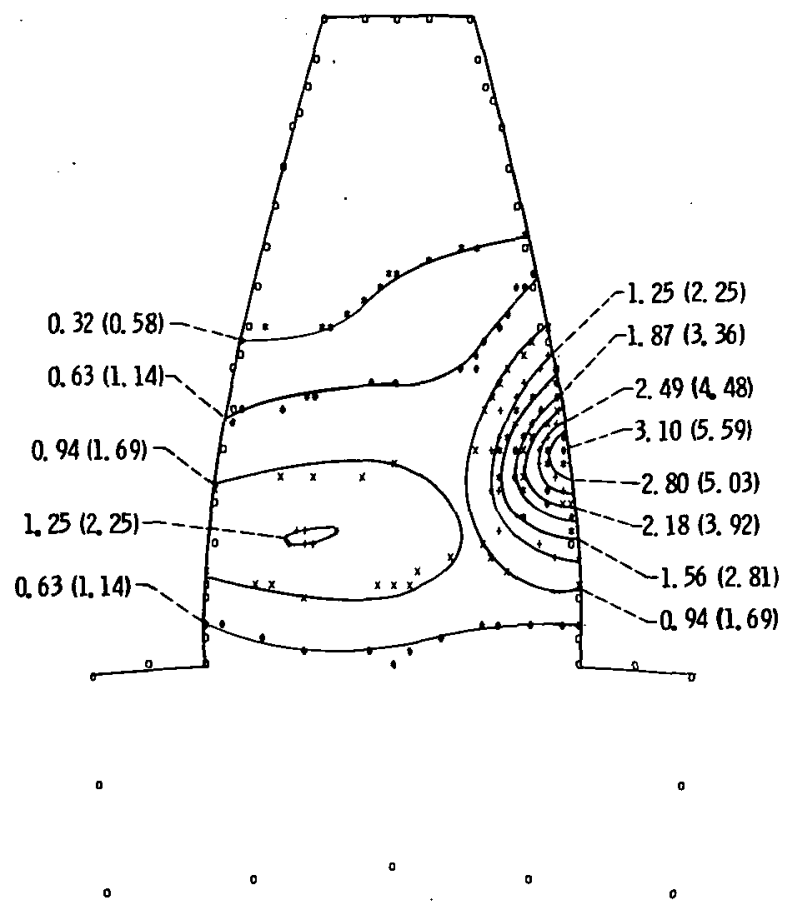

(c) Pinion rotation angle, $13.68^{\circ}$; time, $0.228 \times 10^{-3}$ seconds from point of initial tooth contact.

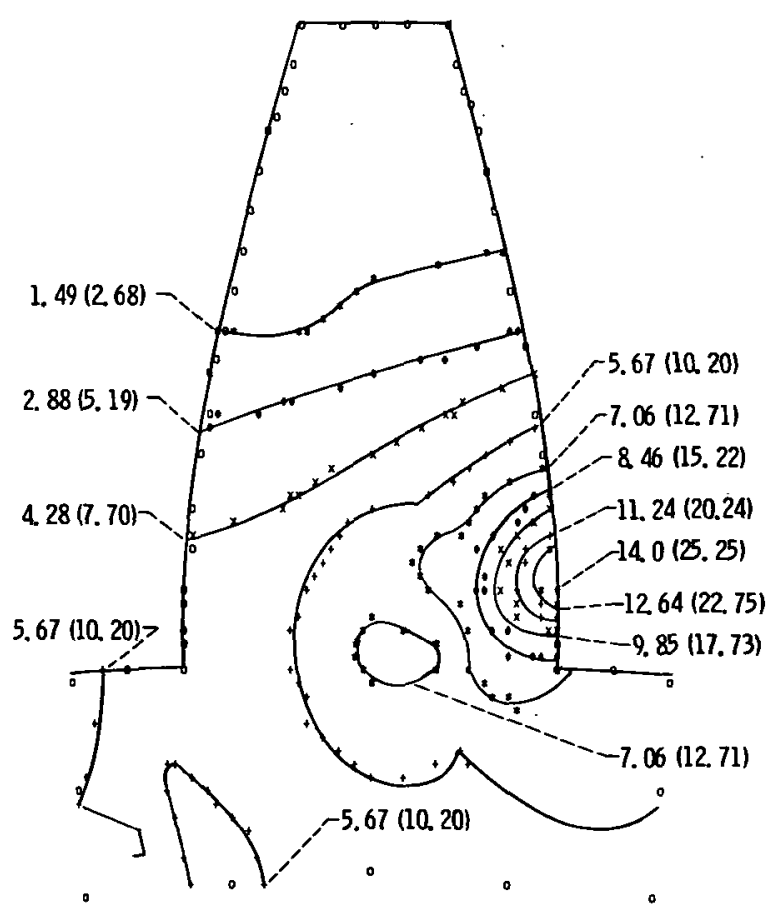

(d) Pinion rotation angle, $20.88^{\circ}$; time, $0.348 \times 10^{-3}$ seconds from point of initial tooth contact

Figure 5. - Transient temperature isotherms using transient analysis with computed heat transfer coefficients, load side and top land cooling only. For 8-pitch spur gear: pitch diameter, $889 \mathrm{~cm}(3.5 \mathrm{in}$.); face width, $0.635 \mathrm{~cm}$ (a. $25 \mathrm{in}$.); speed, $10000 \mathrm{rpm}$; $102 d, 5912 \mathrm{~N} / \mathrm{cm}$ (3378 lb/in.); dimensionless impingement depth, 0.336 . 


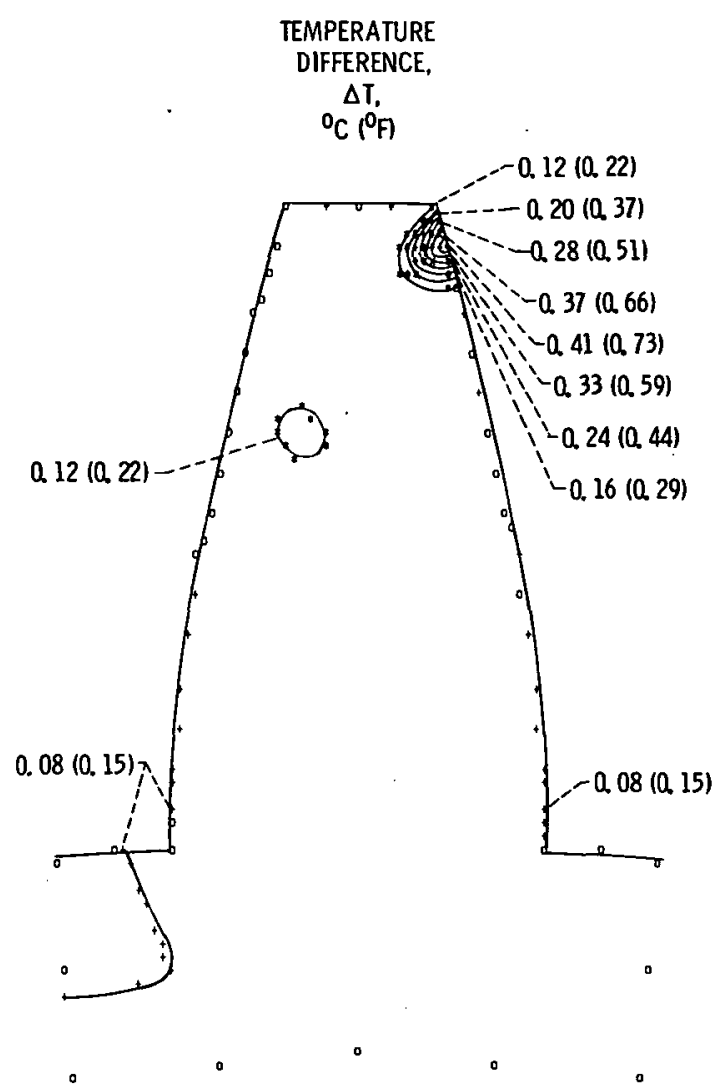

(a) Pinion rotation angle, $0.72^{0}$; time, $0.012 \times 10^{-3}$ seconds from point of initial tooth contact.

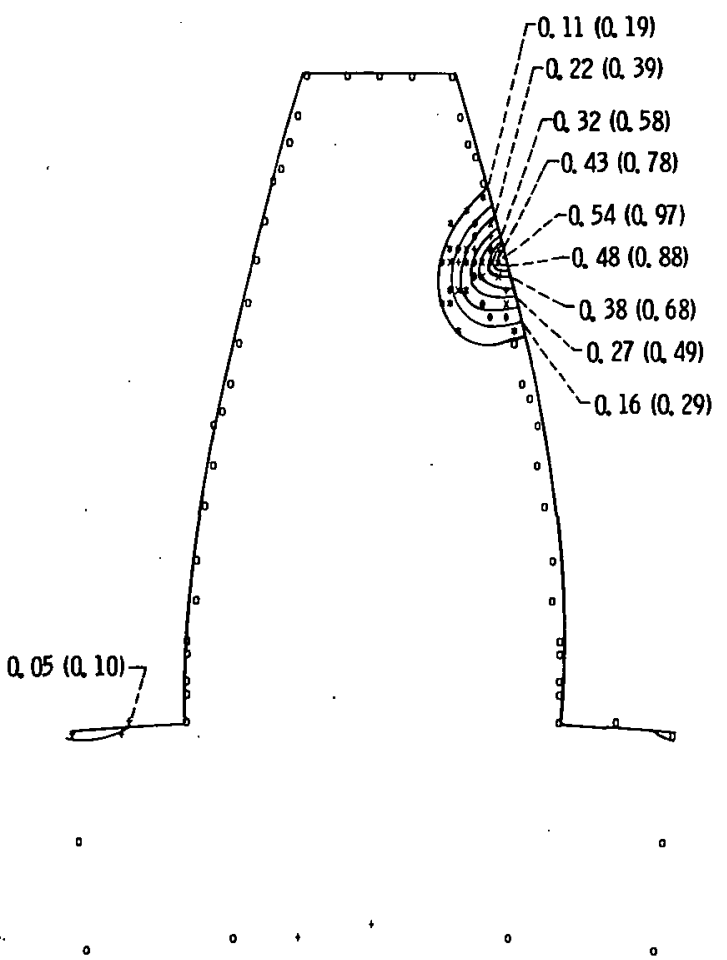

(b) Pinion rotation angle, $5.04^{0}$; time, $Q .08 \times 10^{-3}$ seconds from point of initial tooth contact.

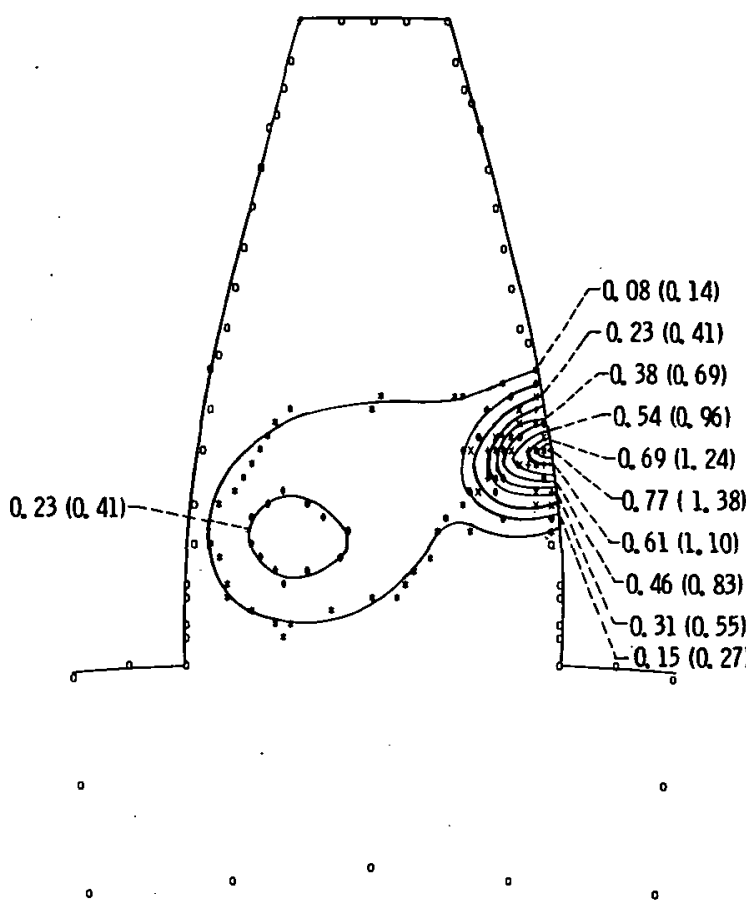

(c) Pinion rotation angle, $13.68^{\circ}$; time, $0.228 \times 10^{-3}$ seconds from point of initial tooth contact.

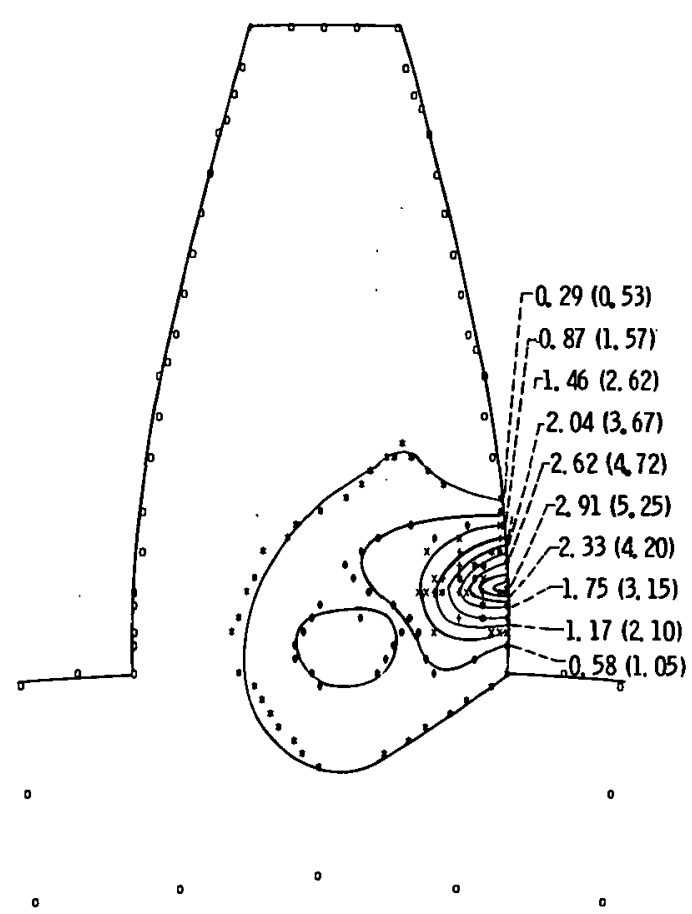

(d) Pinion rotation angle, $20.88^{\circ}$; time, $0.348 \times 10^{-3}$ seconds from point of initial tooth contact.

Figure 6. - Transient temperature isotherms using transient analysis with computed heat transfer coefficients modified by the ratio of the coefficients used in (ref. 1). Cooling of the loaded side, coast side and top land only. For 8-pitch spur gear: pitch diameter, 8.89 cm (3.5 in.); face width, $0.635 \mathrm{~cm}(0.25 \mathrm{in}$.); speed, $10000 \mathrm{rpm}$; normal load, $5912 \mathrm{~N} / \mathrm{cm}(3378 \mathrm{lb} / \mathrm{in}$.); dimensionless impingement depth, 0.336. 


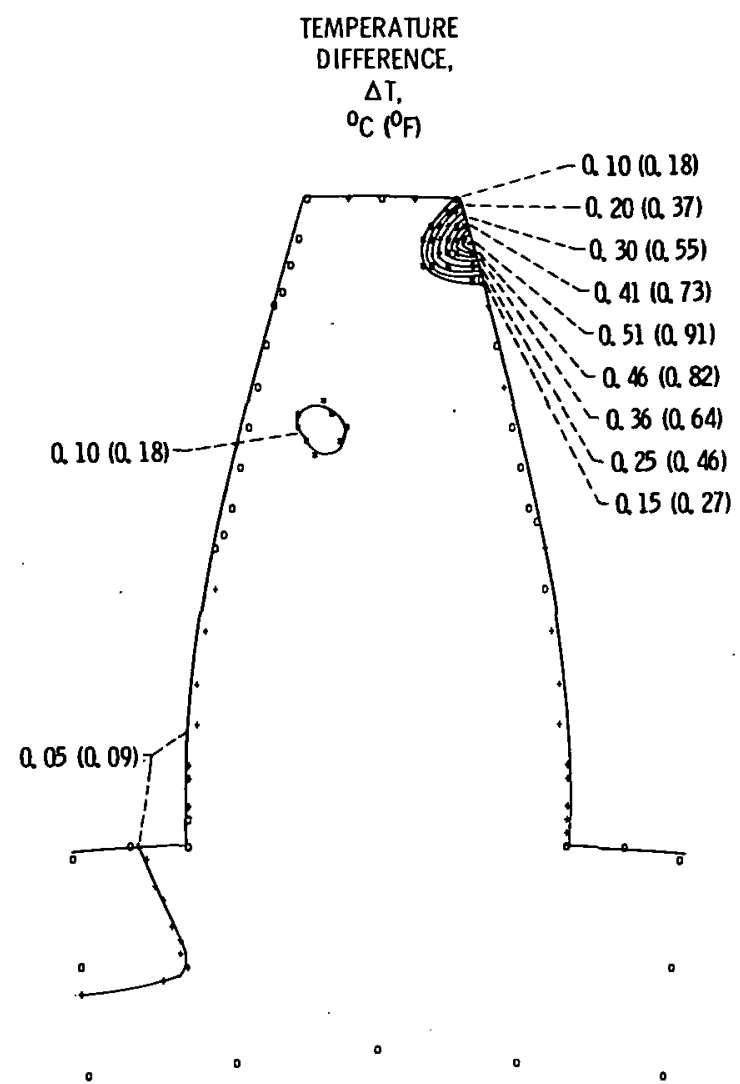

(a) Pinion rotation angle, $0.72^{0}$; time, $0.012 \times 10^{-3}$ seconds from point of initial tooth contact.

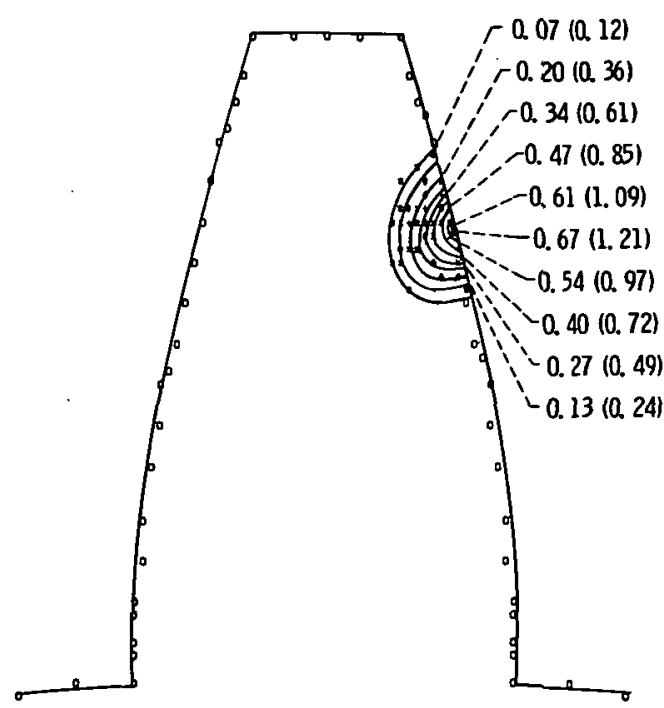

(b) Pinion rotation angle, $5.04^{0}$; time, $0.08 \times 10^{-3}$ seconds from point of initial tooth contact

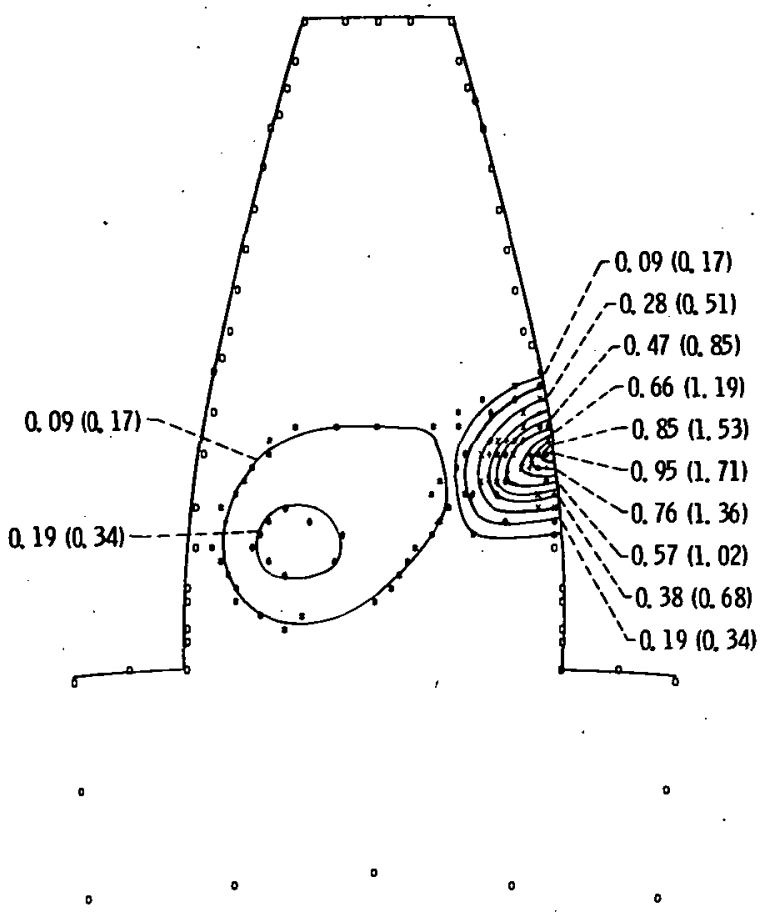

(c) Pinion rotation angle, $13.68^{\circ}$; time, $0.228 \times 10^{-3}$ seconds from point of initial tooth contact.

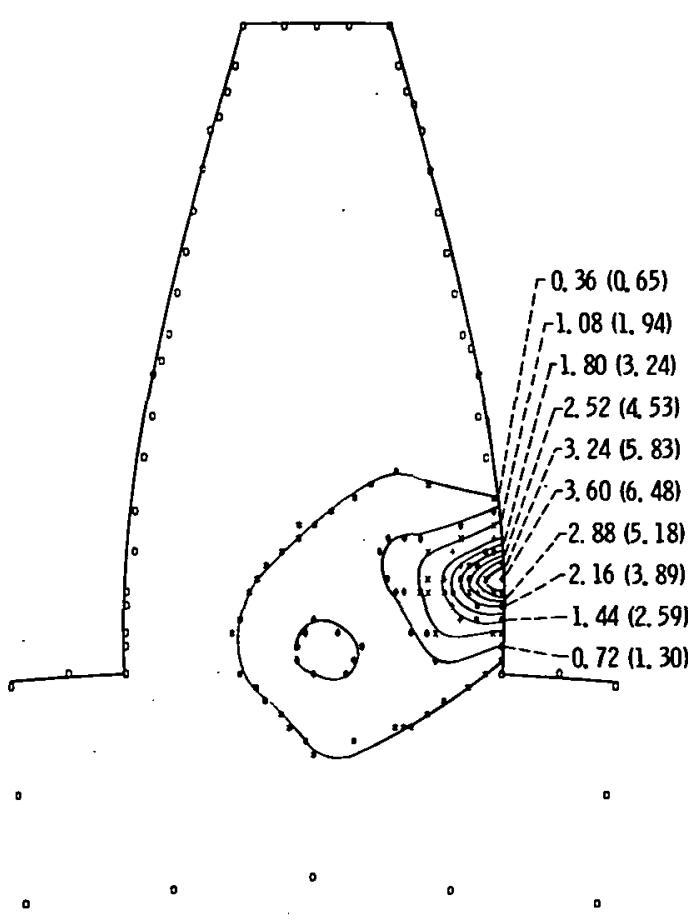

(d) Pinion rotation angle, $20.88^{\circ}$; time, $0.348 \times 10^{-3}$ seconds from point of initial tooth contact.

Figure 7. - Transient temperature isotherms using transient analysis with calculated heat transfer coefficients modified by the ratio of the coefficients used in (ref. 1). Cooling of the loaded side, coast side, top land and end of the teeth. For 8-pitch spur gear: pitch diameter, $889 \mathrm{~cm} \mathrm{(3.5} \mathrm{in.);}$ face width, $0.635 \mathrm{~cm}(0.25 \mathrm{in}$.); speed, $10000 \mathrm{rpm}$; normal load, $5912 \mathrm{~N} / \mathrm{cm}(3378 \mathrm{lb} / \mathrm{in}$.); dimensionless impingement depth, 0. 336 . 


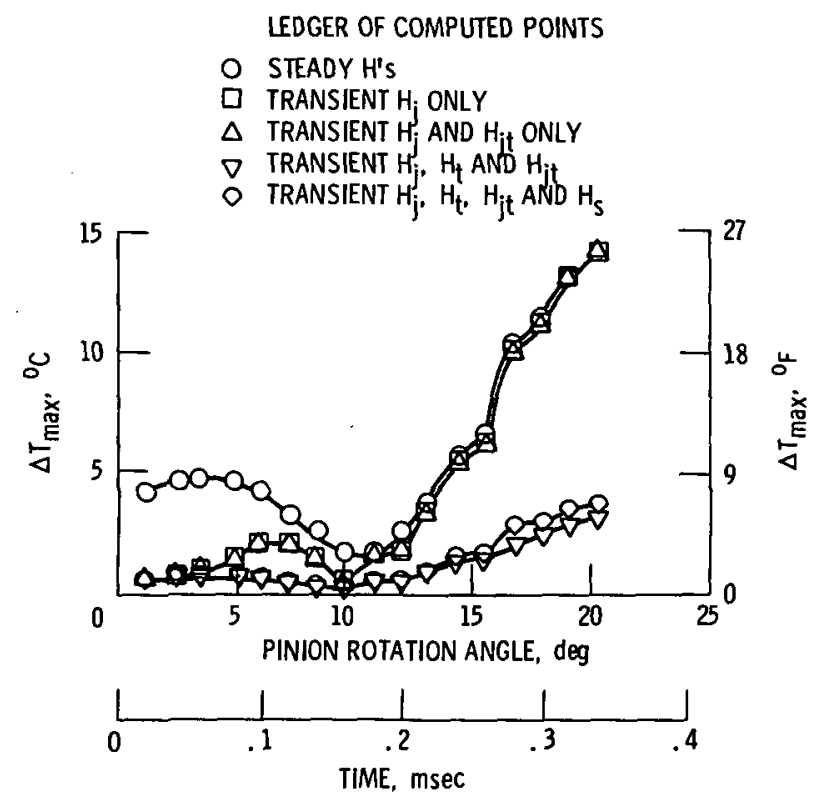

Figure \& - Variation of maximum temperature rise with pinion rotation angle and time. 


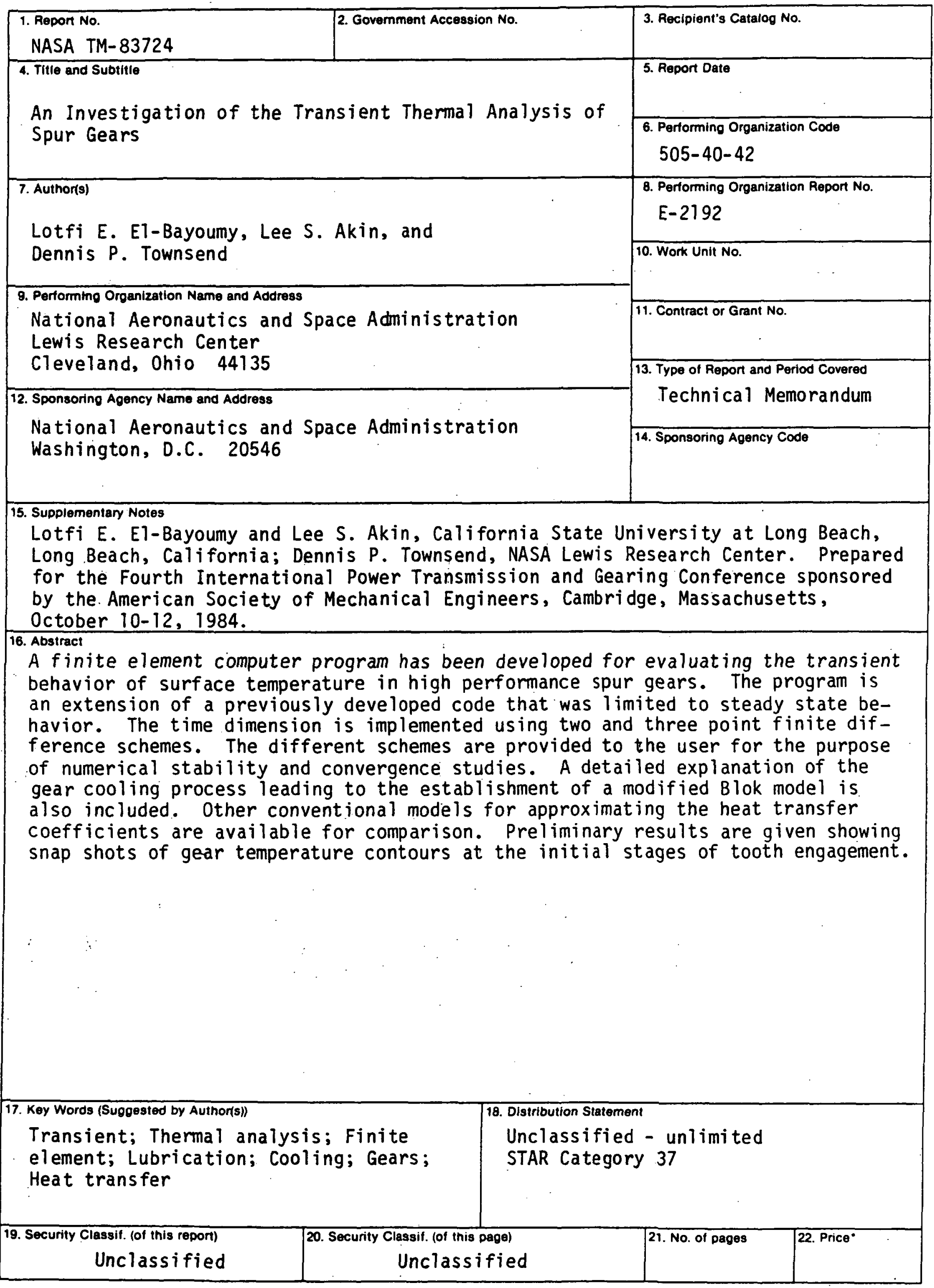


National Aeronautics and Space Administration

Washington, D.C.

20546

Official Business

Penalty for Private Use. $\$ 300$
SPECIAL FOUATH CLASS MAIL BOOK Mational A eroneutics and Spece Administration NASA-451 